\title{
Article
}

\section{Big Data-driven Budgeting and Business Planning}

\author{
Alessio Faccia ${ }^{1 *}$ \\ 1 Coventry University; alessio.faccia@gmail.com \\ * Correspondence: alessio.faccia@gmail.com; Tel.: +44-7425277726
}

\begin{abstract}
The business planning process can be considered as a strategic phase of any business. Given that the business plan is a management accounting tool, there are countless approaches that can be adopted to prepare it since there is no legal requirement, as opposed to obligations relating to financial accounting. However, in general, every business plan consists of a numerical part (budget) and a narrative part. In this research, the author highlights, on the basis of experiences and commonly used theories, a standard process that can be adaptable to the business plan of any type of activity. The use of big data is highlighted as an essential part of feeding the data of almost all the steps of the budget. The author then manages to determine a generally applicable standard process, indicating all the data necessary to prepare an accurate and reliable business plan. A case study will provide adequate support to the demonstration of the immediate applicability of the proposed model.
\end{abstract}

Keywords: Big Data; Business Plan; Budgeting; Budget; Business Strategy.

\section{Introduction}

Countless books and researches have tried to identify the best possible structure for drafting a business plan, such as [1-4], to name a few. On the basis of the specific skills/experiences of the researchers, however, it is possible to observe a orientation in emphasizing the preparation of some parts of it. Given the nature of the business plan that must be adapted to projects, companies, or businesses that are sometimes completely different from each other, some authors [5-6] have pointed out that a generally valid structure is just a chimera. Other authors [7-8] have instead indicated that, given the modular structure of the business plan, divided into sections, paragraphs, or chapters, it is instead possible to identify at least all the possible modules of which a business plan can be made. Having considered many publications, researches, and books, the recurring following basic common modules are identified: a) cover page; b) table of contents; $c$ ) executive summary; d) situation analysis, internal and external; e) business resources; f) business strategy (including the marketing plan); g) budget; h) analysis of variances (risk analysis: best and worst case scenarios); i) attachments and supporting documentation [1-14]. Among all these modules, at least the cover and the budget appear essential, otherwise, rather than a business plan, a company profile could be identified [8]. If the editor of the business plan intends to prepare all the above sections it is evident the absolute centrality of the preparation of the budget which requires, for each item, the identification of the resources and constraints that each choice entails. All the options and hypotheses formulated among the assumptions of the business plan must demonstrate a valid foundation deriving from the application of statistical techniques, official sources, rules of thumb, or simple consolidated practices. In the requisition and identification of this data, it is certainly useful to have access to the so-called big data, which provide not only adequate support, but also a competitive advantage to those who have them available [15-18].

\section{Materials and Methods}

Two main methodologies are used in this research. A systematic literature review is carried out to analyze the best practices in terms of business planning and data mining. A case study is then performed to identify a flexible standard path that can be used for the preparation of any business 
plan. The material used, relating to the first methodology, is mainly attributable to the research carried out on research papers, articles, and books published in international journals and indexed on Scopus, ProQuest, Web of Science, Google Scholar. Although a separate paragraph relating to the literature review has not been prepared, it is reported along with each analysis indicated in the results.

\section{Results}

According to the research, performed using the best resources available as above disclosed, the author came to the identification of the main modules of which a business plan could be made. After analyzing each section in detail, the author further focused on the preparation of the budget, as it is considered the core of any business plan. A specific priority is then assigned to each step, thus leading to the determination of a flexible linear process, albeit standardized, easily applicable to any business plan (whether it refers to a company or a single business).

\subsection{Business Plan Basic Modules}

\subsubsection{Cover page}

It might appear trivial, but any project presented by an entrepreneur usually has a cover, which identifies the essential elements of the document. The cover usually includes the following: Company name; address; telephone/fax/web site/e-mail; company logo; management (president, vice president, commercial director); date of last Business Plan update; copy number (to keep track of copies distributed). In this regard, it should be remembered that the business plan can be drawn up mainly for two purposes: one internal, to verify the feasibility of a project, the other external, to be able to apply for a loan or any other form of financing. Especially in the latter case, a good presentation can certainly help impress potential lenders. Therefore, the use of software specialized in presentation editing appears very useful, being able to draw on a huge number of templates and styles $[1,4,6,19]$.

\subsubsection{Table of contents}

The table of contents, linked to a coherent numbering of all the pages that make up the business plan, offers an easy reading of the document, facilitating the understanding and the immediate identification of the parts that the reader wants to analyze. Especially in the case of business plans made up of many modules and sub-sections, the preparation of a table of contents appears very appropriate.

\subsubsection{Executive summary}

The executive summary includes a brief summary of the entire Business Plan [5], describing alternatively or jointly a company (as a whole) and / or a single project that it wants to develop, to which the business plan is therefore dedicated. In this section, the vision and mission can be indicated. How much ever indicated in this definition, especially for the purposes of correct corporate governance, the determination and use of resources that can help identify a good vision and mission. The executive summary is specifically addressed to the recipient of the Business Plan, therefore, in the event that this is aimed at obtaining a form of financing, it is necessary to clearly report a proposal directly, specifying what is offered and what you ask [20-21]. This module, therefore, consists of an introduction that highlights the main aspects of the plan and development considerations, without ever providing detailed information. To be more effective, this module can usually be prepared last, only after verifying the feasibility of the project and balancing all the necessary resources. The executive summary, when referring to a company as a whole, can also take the form of a so-called company profile, reporting general information about the company presentation. 
3 of 11

\subsubsection{Situation analysis, internal and external (As is)}

The situation analysis examines the differences between current performance and past goals, it includes a careful assessment of current goals and performance specifying how they should be measured (KPI). This represents an input for tools such as SWOT Analysis, a matrix that identifies and articulates all the competitive elements to develop strategies that maximize strengths and opportunities, minimizing weaknesses and threats.

- Internal: strength - weakness;

- $\quad$ External: opportunity - threat.

This module analyzes the target market (market research); any possible networks (alliances with other companies) are identified; the competitors are described; the market context is described by specifying any new legal provisions, changes in the prices of raw materials, new consumption patterns, new production techniques or services offered; the number of potential customers is identified (to continue selling it is necessary to continually expand the range of potential consumers); market segmentation is carried out: evaluation in successive steps, definition of geographical areas for the marketing of the product, characteristics and aspirations of potential customers, characteristics of the organizations with which one wishes to do business [22-24].

It is evident that the availability of such data is of fundamental and strategic importance to feed the various sections that will make up the business plan as they represent the basic assumptions. In the case of big data, therefore, the larger the number and the better the quality of the data available, the more accurate the result of the forecasts that will be included in the budget.

\subsubsection{Business resources}

The business resources section provides a detailed description of operations, legal form, products/services offered, location, management, accounting/control systems, insurance, procurement, markets, organizational structures, staff (job description), security and protection of assets, human, financial, physical and resources, intangibles in general. In this section, not only the resources already available but also those needed must be reported. Also, in this case, the availability of information that is as accurate and updated as possible is essential [1-4,25].

\subsubsection{Business strategy (including the marketing plan)}

The business strategy module expresses the objectives of the business and the strategies to be implemented to achieve them (the objectives must be concrete and specific and can be multiple: to become a leader in the market in particular industries, segments or niches). The strategy must be clearly exposed to guide development of specific programs and activities to follow. The marketing mix, philosophy, price, communication are also expected to be described in this section, determining the choice of targets, distribution methods, promotional activities, product design, timing, location, sector trends (taken and developed by the situation analysis and the organizational plan, if already described in these sections). This section of business strategy can therefore coincide with the marketing plan or can include it. The marketing plan is a planning document that contains the strategy and operational actions implemented by the company to achieve its business objectives. Its purpose is to direct, coordinate, and monitor all the marketing activities that the company implements or plans to implement in a given period of time. Whether referred to a brand, a product, or a specific set of products, it is both a strategic and an operational tool [26-30].

\subsubsection{Budget}

The costs and revenues and related profits are outlined and estimated; this section highlights the expected profits from the implementation of the Business Plan possibly taking into consideration alternative strategies; it includes all documents used to disclose the past, present situation and forecasts for the future; future sales and income are estimated; it should also include a financial needs summary; it expresses the funds allocation; it includes past performance reports to analyze trends, providing the calculation of the relevant ratios; it is prepared like a pro forma financial statement 
(forecasted financial statements), therefore including a cash flow statement, an income statement, and a balance sheet; where applicable a break-even analysis is also carried out. An accurate description of all the elements needed to determine a balanced budget is provided below $[1,4,31]$.

\subsubsection{Analysis of variances (risk analysis: best and worst case scenarios)}

This section specifies how the results of the plan should be calculated; Internal performance data and external environmental relations (benchmarks) are identified for diagnosis and assessments; the results achieved are monitored by comparing them with the objectives; the actions to be undertaken to solve eventually identified problems that can arise (Alternative plans: Plan B, Plan C ...). The main checks that must be carried out concern: knowing how to manage resources and time effectively; uniqueness of the product; right price-setting; timing of the launch of new products/services. In practice, a business does not generally obey the plan. The BP and the information used to compile it are an excellent basis for considering possible variations: slow sales, late collections, changes in commodity prices [32].

\subsubsection{Attachments and supporting documentation}

Attachments serve to support the reports and decisions contained in the main sections of the BP. Not all supporting documents need to be included in each copy of the BP. Examples of attachments are: curricula, commercial information; a copy of the contracts; references; legal documentation: trademark / patent registration. The additional documents required for bank inquiries for obtaining loans are as follows: company profile; Act of incorporation and Statute; any subsequent statutory amendments; any recent sales of shares; updated registration; identity document of the administrator; updated bank credit lines; list of main customers and suppliers; financial statements of the past three years; main contracts/agreements; the company brochures [33-34].

\subsection{Budgeting standardized path}

In this paragraph the standardized path, the outcome of this research is described. For each step, specific needs in terms of big data are highlighted to obtain more accurate results. The identification of the path described below derives from the application of all the concepts mentioned above, of the theories included in countless publications, and from the test carried out on different types of projects. By following this path it is, therefore, possible to always determine a perfectly balanced budget, at least on three-plus-year basis, being able to repeat the process if some subsequent hypotheses prove to be inconsistent or unsustainable. Some of these steps can be grouped (see Figure 1 ), the sequence of the identification of those values can then be reversed within the same group without affecting the determination of the final result. 


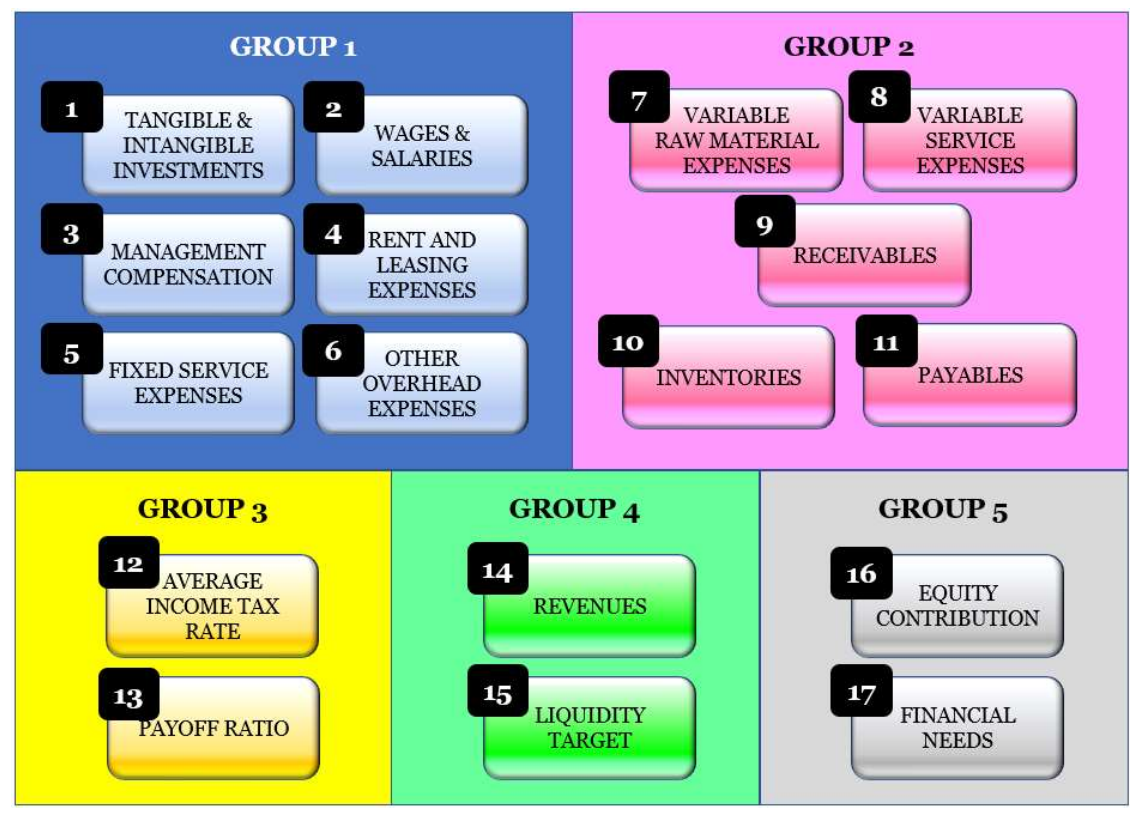

Figure 1. Budgeting groups and steps.

The first group of steps that can be identified is the one related to the fixed costs, those costs that do not depend on the volume of production.

\subsubsection{Investment in tangible and intangible assets}

By long-term-assets in business administration are meant all assets that are used in the company for more than one year, both tangible and intangible. For example a machine, a production plant, or a software. These assets do not run out with use or at the end of the period, but remain within the company for longer periods. The most common tangible assets of durable use in the company are machinery, plants, vehicles, usually identified by the common definition PPE (property plant equipment). Tangible fixed assets are also called technical fixed assets because they include all the production factors or capital goods that are used to carry out the characteristic management of the company. The value and cost of these assets can be obtained by doing careful research on the web, obtaining different estimates, comparing the characteristics of each, verifying price trends, comparing the prices of new and used goods. The depreciation and amortization value can also be identified by having access to databases that estimate the useful life of the assets, as well as to tax tables that impose a specific depreciation rate. The sum of the residual values at the end of each period must be reported in the budget based on the specific amortization plan assumed for each asset. Let's assume a cost of $€ 100,000$ for a plant with an expected useful life of 10 years, as well as the cost of $€ 20,000$ for the acquisition of an industrial patent (intangible), amortizable over 5 years (see Figure 2) [35-36].

\begin{tabular}{|l|r|r|r|r|r|}
\hline FIXED ASSETS & Y1 & Y2 & Y3 & Y4 \\
\hline INTANGIBLE ASSETS & & & & \\
\hline TANGIBLE ASSETS & 16,000 & 12,000 & 8,000 & 4,000 \\
\hline DEPRECIATION / AMORTIZATION & 90,000 & 80,000 & 70,000 & 60,000 \\
\hline
\end{tabular}

Figure 2. Tangible and intangible assets.

\subsubsection{Wages and salaries}

The cost of labor, identified by salaries for employees and wages for workers, can be calculated by identifying different categories of workers and calculating the annual cost for each category, including costs for social contributions and any taxes. By way of example, only one class of workers is assumed, made up of 10 workers, whose average monthly wage is Euro 2000, and whose social 
6 of 11

contribution cost is $20 \%$ of the gross wage. For simplicity, no salary increases or changes in the number of employees are assumed, any changes would still be reflected in the budget (see Figure 3).

\begin{tabular}{|l|c|c|c|c|c|c|}
\hline & Y1 & Y2 & Y3 & Y4 & Y5 \\
\hline WAGES \& SALARIES EXPENSES & 288,000 & 288,000 & 288,000 & 288,000 & 288,000 \\
\hline
\end{tabular}

Figure 3. Wages and salaries

\subsubsection{Management compensation}

The identification of the compensation for the management usually consists of a fixed part and a variable part. As regards the fixed part of their remuneration, this can be identified in a punctual or incremental measure (based on expected inflation). In the example provided it is possible to assume an initial compensation of $€ 50,000$, increased by $1 \%$ each year [35-36] (see Figure 4).

\begin{tabular}{|l|l|r|r|r|r|r|}
\hline & Y1 & Y2 & Y3 & Y4 & Y5 \\
\hline MANAGER'S SALARY EXPENSES & & 50,000 & 50,500 & 51,005 & 51,515 & 52,030 \\
\hline
\end{tabular}

Figure 4. Management compensation

\subsubsection{Rent and leasing expenses}

The cost of any leasing or rentals is usually a cost reported on a stable basis each year, relating to the rents incurred in the period. Sometimes these fees are updated due to inflation. In the example it can be assumed that in the first year the annual cost of the rent is $€ 24,000$ and the lease cost is $€$ 12,000 , with annual increases of 1\% [35-36] (see Figure 5).

RENT / LEASING EXPENSES

Y1 1

\begin{tabular}{|c|c|c|c|}
\hline Y2 & Y3 & Y4 & Y5 \\
\hline 36,360 & 36,724 & 37,091 & 37,462 \\
\hline
\end{tabular}

Figure 5. Rent and leasing expenses

\subsubsection{Service expenses}

Some costs for services are recurring and fixed, in the sense that they do not vary as production varies. Some examples of this type are other industrial costs such as machinery maintenance costs. In the example, it is assumed for simplicity that these costs are absent [35-36].

\subsubsection{Other overhead expenses}

Other costs defined as "overhead" are indirect costs of production, which are generally not variable and which can identify general administrative expenses (or related to them such as electricity related to the offices where the accounting department resides), commercial (such as marketing expenses), or research and development. In the example, it is assumed that these expenses are absent [35-36].

The second group of steps that can be identified is the one related to the variable costs, those costs that depend on the volume of production. In this case, the example only needs to identify the correlation percentages to the drivers to which these costs are linked. These percentages must be carefully weighted and obtained from in-depth statistical analysis. In this case, the availability of big data obviously helps in determining the most accurate assumptions.

\subsubsection{Raw Material expenses}

Raw materials are usually expressed as a given percentage of revenues, obtained as the average of the production efficiency of previous years, or, in the case of a new project, deriving from the industry average. In the example it is assumed that raw materials are expressed as $40 \%$ of revenues [35-36]. 
7 of 11

\subsubsection{Variable Service expenses}

Variable service expenses can also be expressed as a percentage measure of revenue, derived from experience, statistics or other sources. In the example, it is assumed that variable service costs are expressed as $20 \%$ of revenue [35-36].

\subsubsection{Receivables}

Trade receivables can be referred as a percentage of revenues by verifying the average deriving from the historical series of the company or sector. In the example, it is assumed that receivables are equal to $20 \%$ of revenues. In the case of companies, such as retailers, who sell goods only in cash, this value will be $0 \%$ or a very low percentage [35-36].

\subsubsection{Inventories}

The value of inventories must instead be expressed as a percentage of raw materials because they refer to goods not yet sold or to materials incorporated in products still in stock. In the example it is possible to assume a warehouse value equal to $10 \%$ of raw materials [35-36].

\subsubsection{Payables}

Trade payables can be considered as a percentage of the costs relating to raw materials and services (both fixed and variable). In the example, a reasonable percentage of 30\% is assumed [35-36].

The third group of steps that can be identified is the one related to other non-operating rates (below the EBIT) that are usually determined exogenously, as they refer to two stakeholders (shareholders and government) rather than to factors relating to production.

\subsubsection{Average Income tax rate}

The average income tax depends on the state in which the company carries out its business and on any non-deductible costs. In order to determine a plausible value of the average income tax rate, it is necessary to verify the effective rates available from various sources and from the historical series of the sector and of the company [35-36].

\subsubsection{Payoff ratio (retention earnings rate)}

Once the value of the net profit has been calculated, it will then be necessary to determine how much of this profit should be distributed to shareholders and how much retained (retained earnings). The decision is up to the shareholders in the annual general meeting, in any case, especially in the case of drafting a business plan for obtaining loans, it is appropriate to disclose that at least part of the profits are retained to demonstrate the shareholders' willingness to continue to invest in the business. The payoff ratio indicates the ratio between the portion of profits that it is intended to retain and the total net profits. In the example, a percentage of $25 \%$ is assumed [35-37].

The fourth group is made of one step only: the revenues, since it is the main driver that will determine the variable elements of the budget and therefore the final results in terms of profit or loss.

\subsubsection{Revenues}

Having identified fixed and variable costs, it is possible to consider the break-even point as a reference parameter to determine a minimum value of revenues to be indicated in the budget in order not to incur losses. The identification of break-even, in terms of minimum revenues, is therefore considered as the ratio between fixed costs (identified in the Group 1) divided by the difference 
between $100 \%$ and the percentages of raw materials and variable service expenses (identified in the Group 2). The value of the revenues can therefore be determined in various ways. Applying a markup with respect to the value of revenues for the break-even; promptly indicating the revenues for each year relating to specific forecasts or indicating a value of revenues in line with the trend of previous years and predicting sustainable (credible) growth of these revenues in subsequent years. In the example we assume revenues equal to $€ 1,100,000$, having previously identified a break even revenue value of $€ 970,000$, obtained from the following calculation [14,000 depreciation $+288,000$ wages $+50,000$ manager's contribution $+36,000$ rent and leasing) / (100\% $-40 \%$ raw materials $-20 \%$ services). As it is disclosed in Figure 5, the identification of the revenues will automatically lead to the calculation of all the items of the Group 2 and Group 3: revenues, raw materials, service expenses (variable), inventories, receivables and payables. Changes in Cost of Goods Sold (COGS) must be also considered in the income statement as the same amount (with a negative sign) of the inventory in the first year [35-36] (see Figure 6).

\begin{tabular}{|c|c|c|c|c|c|c|}
\hline & BUDGET & BUSINESS PLAN & I AND INCOME & E STATEMENT & & \\
\hline & & Y1 & Y2 & Y3 & Y4 & Y5 \\
\hline & FIXED ASSETS & & & & & \\
\hline & INTANGIBLE ASSETS & 16,000 & 12,000 & 8,000 & 4,000 & - \\
\hline & TANGIBLE ASSETS & 90,000 & 80,000 & 70,000 & 60,000 & 50,000 \\
\hline 5 & FINANCIAL INVESTMENTS & - & - & - & - & - \\
\hline 2 & RECEIVABLES & 220,000 & 222,200 & 244,420 & 251,753 & 259,305 \\
\hline$\$$ & CASH \& BANK & - & 97,875 & 43,748 & 4,056 & 40,248 \\
\hline 㐫 & TOTAL ASSETS & 370,000 & 260,765 & 327,556 & 362,047 & 401,414 \\
\hline & SHAREHOLDER'S CAPITAL & - & - & - & - & - \\
\hline & RETAINED EARNINGS (PREVIOUS) & & 18,240 & 28,876 & 48,552 & 70,281 \\
\hline & NET INCOME / NET LOSS & 72,960 & 42,545 & 78,702 & 86,918 & 97,758 \\
\hline & TOTAL REVENUES & $1,100,000$ & $1,111,000$ & $1,222,100$ & $1,258,763$ & $1,296,526$ \\
\hline & RAW MATERIAL EXPENSES & 440,000 & 444,400 & 488,840 & 503,505 & 518,610 \\
\hline & SERVICE EXPENSES & 220,000 & 222,200 & 244,420 & 251,753 & 259,305 \\
\hline 5 & RENT / LEASING EXPENSES & 36,000 & 36,360 & 36,724 & 37,091 & 37,462 \\
\hline 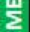 & MANAGER'S SALARY EXPENSES & 50,000 & 50,500 & 51,005 & 51,515 & 52,030 \\
\hline$\frac{w}{\alpha}$ & WAGES \& SALARIES EXPENSES & 288,000 & 288,000 & 288,000 & 288,000 & 288,000 \\
\hline 知 & DEPRECIATION / AMORTIZATION & 14,000 & 14,000 & 14,000 & 14,000 & 14,000 \\
\hline 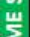 & CHANGES IN COGS & 44,000 & 440 & 4,444 & 1,467 & 1,511 \\
\hline 용 & EBIT (EARNINGS BEFORE INTEREST \& TAXES) & 96,000 & 55,980 & 103,555 & 114,366 & 128,629 \\
\hline$\underline{z}$ & INTEREST EXPENSES & - & - & - & - & - \\
\hline & EBT (EARNINGS BEFORE TAXES) & 96,000 & 55,980 & 103,555 & 114,366 & 128,629 \\
\hline
\end{tabular}

Figure 6. Budget after the identification of the revenues

\subsubsection{Liquidity target}

Since all companies cannot ignore the determination of a certain liquidity buffer to be kept available for daily operations, a specific percentage of liquidity (target) must be added to the value of assets calculated so far. Assuming that this percentage, in the example is $5 \%$ of the other assets [in the example the liquidity needed can be then calculated as follows $(€ 99,040 * 5 \%) /(1-5 \%)=€ 19,474]$. The new gap (total financial needs) to be filled therefore becomes $€ 118,514$ (as a sumo of $€ 99,040$, previous gap, plus the liquidity target $€ 19,474)$.

The fifth and last group of steps that can be identified is the one related to the financing alternatives available to the company: risk capital or borrowed capital. 


\subsubsection{Equity contributions}

Considering that the primary source of financing of the company is given by the equity invested by the shareholders, if this is sufficient to bridge the gap between the value of the assets (in the example $€ 118,514)$, it will not be necessary to request additional external financing from banks or other lenders. Assuming then that the capital invested by the shareholders is $€ 50,000$, the net residual gap to be financed by the banks or other lenders will be $€ 68,514(118,514-50,000)$.

\subsubsection{Financial needs}

The remaining gap arising from the excess funding needed to cover all assets $(€ 68,514)$ must be financed by considering a given interest rate. The value of the loan must be higher than the gap identified in the previous step as it must also be able to cover the interests that represent an additional cost. In the example, considering an interest rate of $5 \%$ and a French amortization plan with constant installments, for a repayment period of 10 years, the value of the loan to be obtained is $€ 77.636$, obtained through the properly configured excel objective search function. Once this last step has been completed, it is easy to verify how all the years, even the following ones, are perfectly balanced and obtained through simple data projections, using the cash and bank value as liquidity to be balanced each year between assets and liabilities [35-36] (see Figure 7).

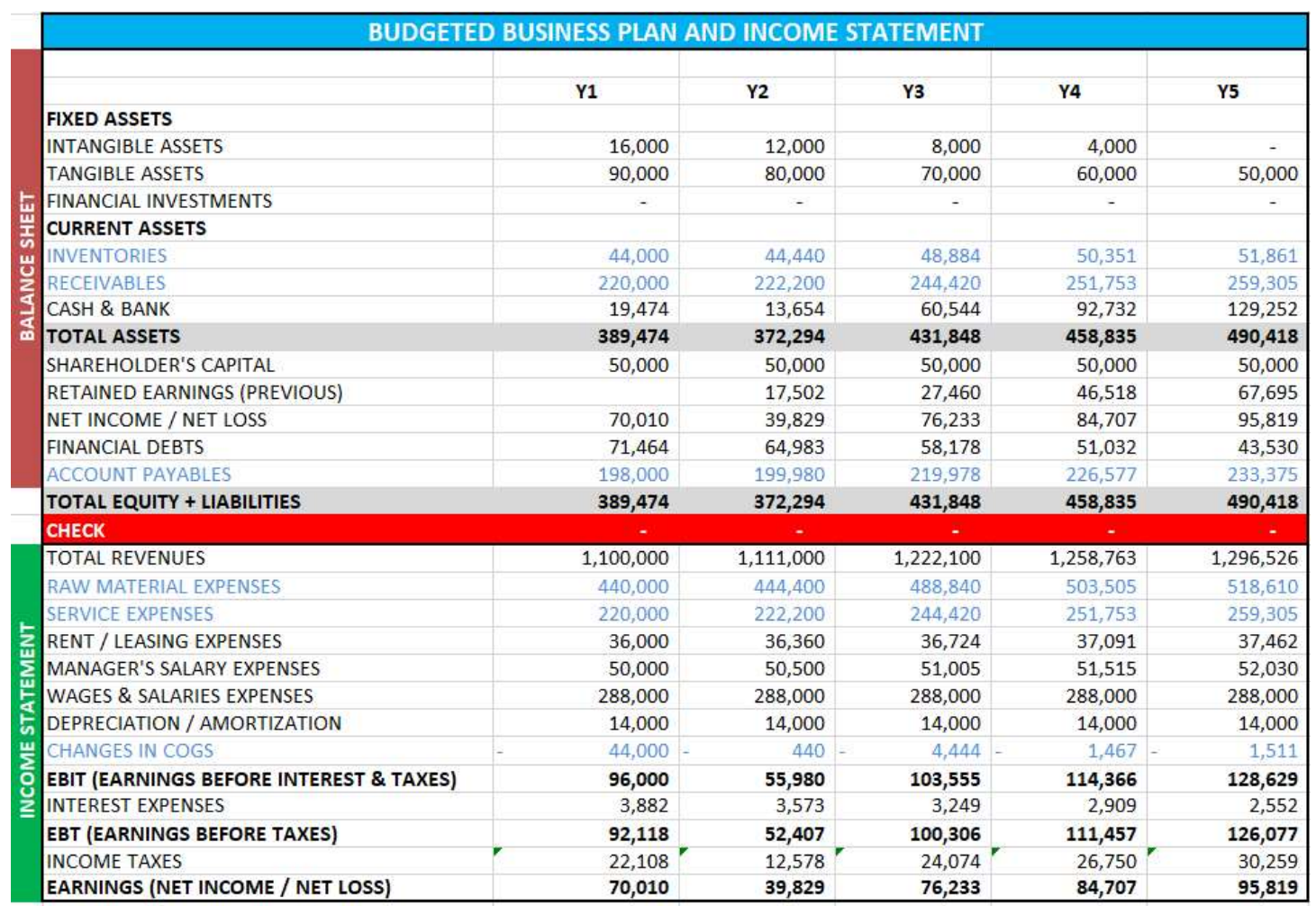

Figure 7. Final balanced budget, according to all the assumptions provided

\section{Discussion}

It is easy to see how the use of such a technique, following the indicated path, allows an essential and practical standardization of the budgeting process. The flexibility and general applicability of this process is linked to the rigorous application of accounting rules, combined with the logic that involves the determination of any project: a) identification of the necessary resources divided into fixed (Group 1) and variable (Group 2) values; b) consideration of external variables such as payoff ratio and income tax rate (Group 3); c) identification of a sustainable revenue value, compared with break-even, intended as the minimum revenue value necessary to ensure the viability of the business (Group 4); and finally d) identification of sources of funding as a combination of risk capital 
(provided by shareholders) and borrowed capital. The usefulness and flexibility of this methodology is even more highlighted by the fact that, when one of the variables considered varies, depending on the need to vary the assumptions (because they are obsolete or because they are not consistent or unsustainable), it is necessary to change only some elements of the subsequent groups, returning to identify a perfectly balanced budget without having to start from scratch.

The possibility of implementing an excellent budget is certainly also dependent on the degree of integration of the information available from big data with company information systems in general, the greater the integration the better the possibility of developing a better budget. Accounting information systems, but especially ERPs, prove to be essential for the integration and development of adequate and reliable budgets [38-40].

Finally, the use of big data is undoubtedly essential in determining the assumptions of each step for the preparation of the business plan in general, but above all of the details necessary to formulate the hypotheses underlying each step of the budget. It is therefore possible to conclude that, for the determination of any business plan, of which the process described in this research is only a case study, data accuracy and access to big data constitute a huge competitive advantage for every company, in terms of forecast accuracy and reliability of their projects. It is no less important to note that the validity of the assumptions deriving from the application of big data allows a conscious discernment in the context of capital budgeting choices between feasible and non-feasible, more or less profitable projects.

Funding: This research received no external funding.

Conflicts of Interest: The author declares no conflict of interest.

\section{References}

1. Bradfield, R., Wright, G., Burt, G., Cairns, G., \& Van Der Heijden, K. The origins and evolution of scenario techniques in long range business planning. Futures, 2005, 37(8), 795-812.

2. Lasher, W. 2010. The Perfect Business Plan Made Simple: The best guide to writing a plan that will secure financial backing for your business. Broadway Books, 2010.

3. Williams, K. Brilliant Business Plan: What to know and do to make the perfect plan. Pearson UK, 2012.

4. Sahlman, W. A. How to write a great business plan. Harvard business review, 1997, 75(4), 98-109.

5. Abrams, R. M. The successful business plan: secrets \& strategies. The Planning Shop. 2003.

6. Berry, T.. The plan-as-you-go business plan. Entrepreneur Press. 2008.

7. Pinson, L.. Anatomy of a Business Plan: A Step-by-step Guide to Building the Business and Securing Your Company's Future. Aka associates, 2008.

8. Finch, B.. How to write a business plan. Kogan Page Publishers, 2013, (Vol. 35).

9. $\mathrm{Xu}, \mathrm{X}$. . Compose the Business Plan. In Introduction to Entrepreneurship, Springer, 2020. pp. 139-163. Singapore.

10. Türko, E. S.. Business plan vs business model canvas in entrepreneurship trainings, a comparison of students' perceptions. Asian Social Science, 2016. 12(10), 55-62.

11. Matović, I. M.. Evolution of the Business Plan in Contemporary Business. In Proceedings of the 17th International RAIS Conference on Social Sciences and Humanities. 2020 (pp. 71-76). Scientia Moralitas Research Institute.

12. Rigby, D. K., Spits, J., \& Berez, S.. An Agile Approach to Budgeting for Uncertain Times. Harvard Business Review, 2020.

13. Kepczynski, R., Jandhyala, R., Sankaran, G., \& Dimofte, A.. Integrated Business Planning. Management for Professionals, 2018.

14. Blumentritt, T.. Integrating strategic management and budgeting. Journal of business strategy. 2006.

15. Warren Jr, J. D., Moffitt, K. C., \& Byrnes, P.. How Big Data will change accounting. Accounting Horizons, 2015. 29(2), 397-407.

16. Hassani, H., Huang, X., \& Silva, E. Digitalisation and big data mining in banking. Big Data and Cognitive Computing, 2018. 2(3), 18.

17. Ajah, I. A., \& Nweke, H. F. Big data and business analytics: Trends, platforms, success factors and applications. Big Data and Cognitive Computing, 2019. 3(2), 32. 
18. Moro Visconti, R., Montesi, G., \& Papiro, G. Big data-driven stochastic business planning and corporate valuation. Corporate Ownership \& Control, 2018, 15(3-1), 189-204.

19. Karlsson, T., \& Honig, B. Judging a business by its cover: An institutional perspective on new ventures and the business plan. Journal of Business Venturing, 2009. 24(1), 27-45.

20. Frese, M.. Executive summary, conclusions, and policy implications. Success and failure of microbusiness owners in Africa: A psychological approach, 2000. 161-190.

21. Lamoureux, K., Campbell, M., \& Smith, R.. High-Impact Succession Management. Executive Summary. Center for Creative Leadership (NJ1), 2009.

22. Mapulanga, P.. SWOT analysis in the planning of information services and systems in university libraries. The Bottom Line. 2013.

23. Welsch, G. A., Hilton, R. W., \& Gordon, P. N.. Budgeting: profit planning and control. Englewood Cliffs: Prentice-Hall. 1988.

24. Hope, J., \& Fraser, R.. Beyond budgeting. Strategic Finance, 2000. 82(4), 30.

25. Fernández-Guerrero, R., Revuelto-Taboada, L., \& Simón-Moya, V. The business plan as a project: an evaluation of its predictive capability for business success. The Service Industries Journal. 2012, 32(15), 2399-2420.

26. Westwood, J.. How to write a marketing plan. Kogan Page Publishers. 2013.

27. Cohen, W. A.. The marketing plan. John Wiley \& Sons. 2005.

28. Jain, S. C., Haley, G. T., Voola, R., \& Wickham, M.. Marketing planning \& strategy. South-Western College Pub.. 2000.

29. Cravens, D. W., \& Piercy, N.. Strategic marketing (Vol. 7). Columbus: McGraw-Hill. 2006.

30. Aaker, D. A., \& Adler, D. A. . Developing business strategies. New York, NY: John Wiley E Sons. 2001.

31. Jensen, M. C.. Corporate budgeting is broken, let's fix it. Harvard business review, 94-101.

32. Lev, B. (1969). An information theory analysis of budget variances. The Accounting Review, 2001. 44(4), 704-710.

33. Di Francescomarino, C. Supporting Documentation and Evolution of Crosscutting Concerns in Business Processes. In ICSOC PhD Symposium. 2008. (Vol. 421).

34. McKeever, M.. How to write a business plan. Nolo. 2016.

35. Faccia, A., \& Mosco, D.. Understanding the Nature of Accounts Using Comprehensive Tools to Understand Financial Statements. Financial Markets, Institutions and Risks, 2019. 3(3), 18-27.

36. Faccia, A., \& Manni, F.. Financial Accounting: Text and cases. Aracne Editrice. 2019.

37. Nissim, D., \& Penman, S. H.. Ratio analysis and equity valuation: From research to practice. Review of accounting studies, 2001. 6(1), 109-154.

38. Faccia, A., \& Mosteanu, N. R.. Accounting and blockchain technology: from double-entry to tripleentry. The Business \& Management Review, 2019. 10(2), 108-116.

39. Faccia, A., Al Naqbi, M. Y. K., \& Lootah, S. A.. Integrated Cloud Financial Accounting Cycle: How Artificial Intelligence, Blockchain, and XBRL will Change the Accounting, Fiscal and Auditing Practices. In Proceedings of the 2019 3rd International Conference on Cloud and Big Data Computing. 2019. (pp. 31-37).

40. Faccia, A.. Data and Information Flows: Assessing Threads and Opportunities to Ensure Privacy and Investment Returns. In Proceedings of the 2019 3rd International Conference on Cloud and Big Data Computing. 2019. (pp. 54-59). 